\title{
12. ALGUNAS REFLEXIONES SOBRE LA EFECTIVIDAD DE LOS DERECHOS Y LAS LIBERTADES
}

\author{
REMEDIO SÁNCHEZ FERRIZ \\ Catedrática de Derecho Constitucional \\ Universidad de Valencia
}




\section{SUMARIO}

I. A MOdo de PRESENTACIÓN.-II. RELECTURA deL ART. 53: REIVINDICACIÓN DE LOS DERECHOS «MENOS FUERTES».-1. El art. 53.1. 2. El artículo 53.3. III. LA CULTURA DE LOS DERECHOS Y LAS LIBERTADES COMO tAREA ESENCIAL DEL ESTAdo Constitucional.-1. Operatividad del enfoque. 2. La enseñanza de los derechos en España. IV. REFLEXIÓN SOBRE EL CAPÍTULO V O LA SUSPENSIÓN DE GARANTIAS.-1. Respeto de los derechos es, también, respeto a su "suspensión". 2. El riesgo de "normalizar" el Derecho excepcional. 


\title{
12. ALGUNAS REFLEXIONES SOBRE LA EFECTIVIDAD DE LOS DERECHOS Y LIBERTADES
}

\author{
POR \\ REMEDIO SÁNCHEZ FERRIZ \\ Catedrática de Derecho Constitucional \\ Universidad de Valencia \\ I. A MODO DE PRESENTACIÓN
}

Es difícil emprender el estudio, o siquiera una aproximación a las garantías de nuestro sistema constitucional de Derechos y Libertades en tan estrechos límites, tanto por la pluralidad de institutos previstos para su defensa como por la extraordinaria importancia del tema en torno al cual se centra el Derecho Constitucional actual. Un derecho vale jurídicamente, dice el Prof. TORRES, lo que valen su garantías y, si recordamos el famoso art. 16 de la Declaración francesa de 1789 , en torno al tema se centra la existencia, o no, de la verdadera Constitución.

Con ser esencial tal enfoque, mucha agua ha corrido desde entonces y muchos frutos ha dado, cuanto menos en nuestra área cultural, la larga marcha por la libertad de los cuales nuestra Constitución ofrece un buen repertorio. Ello hace más compleja si cabe nuestra reflexión pues, siendo por principio, y por efecto de tales luchas históricas, la más jurídica de las cuestiones constitucionales, alcanza hoy, también, perfiles políticos y sociológicos que más allá de su legitimación, alcanzan a los mismos comportamientos de los poderes públicos $y$, en definitiva, condicionan la forma de gobierno y la del propio Estado.

Con este enfoque, amplio, y si se quiere ajeno a nuestras propias reflexiones anteriores sobre el tema, emprendemos ahora esta aproxima- 
ción a lo que, más que garantías, hemos querido titular efectividad de los derechos y las libertades. La opción no sólo responde a los límites de esta exposición sino también a la situación en que el tema se halla actualmente a partir del tratamiento doctrinal que ha recibido. No son pocos ni carentes de valor los estudios en que se exponen y analizan tanto los contenidos constitucionales como la interpretación normativa y jurisprudencial que de los mismos se ha llevado a cabo en trece años de experiencia constitucional. A ellos me remito en lo que se refiere al tratamiento jurídico de los medios de defensa de los derechos y las libertades para poder, aquí y ahora, exponer con brevedad lo que creo ha sido omitido en mayor medida. $\mathrm{Ni}$ tampoco propondremos la reforma del artículo 53 pues no es éste un punto en el que yo enmendaría la plana al constituyente: De completo y riguroso ha calificado PRIETO SANCHíS el sistema español de protección de los derechos; tal vez, con la experiencia de los últimos años la expresión pueda parecer exagerada y, lógicamente, no faltan aspectos cuya revisión es aconsejable y hasta imperiosa pero se trata de aspectos, disfunciones o inconvenientes que se han planteado en y a partir del desarrollo normativo; no, de los dictados constitucionales.

Por ello, la virtualidad del enfoque reside tanto en las posibilidades de plantear un debate sobre nuestro sistema de derechos constitucionales observándolo desde la realidad, cuanto como hipótesis de trabajo para una posterior y más meditada reflexión que me propongo hacer. El artículo 53 es un buen marco jurídico para la eficacia de los derechos. Pero sabemos bien que las libertades nunca son definitivamente adquiridas y que su defensa necesita de un esfuerzo permanente para evitar ese contraste entre lo que BOBBIO llama las solemnes declaraciones y su realización, "entre la grandiosidad de las propuestas y la miseria de los cumplimientos».

$\mathrm{Ni}$ que decir tiene que en nuestra corta experiencia constitucional son muchos los ejemplos con que se podría mostrar la intervención del legislador y los Tribunales, constitucional y ordinarios, en favor de la construcción del sistema de derechos y libertades de que hoy gozamos así como del desarrollo de sus garantías (baste pensar como más recientes, en la ampliación del procedimiento preferente y sumario del amparo judicial al ámbito laboral o las previsiones contenidas al respecto en el proyecto de Ley del Régimen Jurídico de las Administraciones Públicas) pero ello no impide la existencia de altibajos en tal proceso como también la presencia de algún que otro, peligroso, desacierto. La reciente polémica sobre la Ley de Seguridad Ciudadana, ya vigente, nos sitúa forzosamente en el camino de la reflexión sobre la irreversibilidad del proceso de consolidación de los derechos fundamentales, y lo mismo cabe decir si observamos las recientes actitudes del Poder ejecutivo en punto a la libertad de expre- 
sión, algunas de las cuales han quedado asumidas por el Parlamento en recientes disposiciones normativas.

Nos hemos referido a algo tan poco jurídico como las «actitudes" previas a la adopción de medidas restrictivas porque lo importante ya no es contar con garantías jurídicas constitucionalizadas, que esas las tenemos, sino avanzar en el proceso de consolidación en el respeto a la dignidad humana $y$ a los derechos que le son inherentes hasta llegar a un punto de no retorno, aquel en que la sensibilidad por la libertad llega a impregnar todo el tejido social. Pues tan importante como el establecimiento de garantías formales es el compromiso social y político de velar por su más cumplido respeto en cuyo objetivo es decisivo el fomento de una "cultura de los derechos fundamentales" o, si se prefiere, también de una "pedagogía de la libertad", con esta perspectiva iremos reflexionando a partir de ahora sobre el artículo 53 y sobre el 55 de la Constitución; y en el desarrollo del discurso, se evidenciarán lógicamente las inevitables conexiones entre ambos.

Por lo demás, en el ámbito docente en que nos movemos en nuestra actividad profesional, no puede faltar una referencia a la más olvidada de las políticas en favor de los derechos y las libertades: la de su enseñanza o sensibilización de la última generación de los ciudadanos, los que siéndolo ya de pleno derecho, tal vez carecen del conocimiento suficiente del propio régimen en el que han crecido sin que, además, cuenten con el revulsivo (o si se prefiere entusiasmo por la libertad) de haber conocido la carencia de la misma por ser también desconocedores de la experiencia española anterior.

El interés del enfoque no queda desmentido por la complitud de las garantías jurídicas de nuestro artículo 53 a que antes nos hemos referido. Pues, como en tantas otras cuestiones nuestra Constitución en este punto no hace sino recoger la experiencia y los "avances" operados en los países democráticos desde la Segunda Postguerra Mundial. Ello nos ofrece una plataforma excepcional para la efectividad de nuestro sistema constitucional de derechos, pero también nos obliga a reflexionar sobre el más delicado de sus perfiles: el de la posible falta de arraigo social del propio texto constitucional. Si en los sistemas constitucionales democráticos que nos han servido de modelo el nivel alcanzado ha sido fruto de una progresiva y ya consolidada labor jurisprudencial y doctrinal primero, y legislativa después, que a partir de textos constitucionales técnicamente menos avanzados que el nuestro, han ido reflejando de cualquier modo la evolución del sentir social, en nuestro caso hay que evitar que la situación sea o evolucione inversamente; la plataforma o el punto de partida es, jurídicamente, sólido pero su aplicación exige de una política de derechos fun- 
damentales entendida como tarea decisiva del Estado constitucional (en el sentido propuesto por HÄBERLE, del que después se hablará) y, más aún, de la "cultura de los derechos fundamentales" como mentalidad o sentimiento arraigado en la sociedad.

\section{RELECTURA DEL ARTÍCULO 53: REIVINDICACIÓN DE LOS DERECHOS «MENOS FUERTES»}

Nuestra reflexión sobre el art. 53 ha de ser breve por cuanto, apartándose del habitual análisis tendente a desmenuzar cuantos elementos jurídicos contiene, se limitará ahora a la propuesta de un nuevo enfoque o "relectura" de dicho artículo.

Nuestra Constitución es "discriminatoria" con los derechos. Ello es incontestable cualquiera que sea la interpretación que del conjunto de los mismos se quisiera hacer, como ya he expuesto en otras ocasiones. Tampoco ahora criticaré la existencia de los grados, a mi juicio innegable y con decisivas consecuencias en el orden jurídico, pero sí creo que vale la pena propiciar una interpretación sistemática que, sin forzar el esquema constitucional, permita ir reforzando la defensa y respeto de los más débiles de los derechos reconocidos.

Creo que hasta ahora hemos estudiado el art. 53 observándolo desde su cúspide, desde la protección que a los derechos fundamentales y a las libertades públicas otorga su segundo párrafo. Con tal perspectiva, por lo demás útil, el resto del artículo podría parecer marginal. Basta una ojeada a la producción doctrinal para comprobar este hecho. Sólo dos ideas apuntaremos aquí, en cambio, sobre el más protegido y estudiado de los párrafos del artículo 53, el segundo: la primera, relativa a una de las principales disfunciones apuntadas por la doctrina y usufridas" por el T.C.: el uso excesivo e inadecuado del Recurso de Amparo constitucional. La segunda, tal vez responsable de la anterior, la negligencia del legislador que tras trece años de vigencia constitucional, no ha procedido a desarrollar el art. 53.2 en punto a la regulación del "amparo judicial".

Respecto del primer punto, la experiencia constitucional ha puesto de relieve los riesgos de un uso inapropiado del Recurso de Amparo; el problema, como pone de manifiesto la doctrina, ya no es sólo del bloqueo que el elevado número de recursos provoca en el T.C. sino, además, de la incompleta protección que se presta a los derechos de los ciudadanos. Piénsese en la importancia de la inmediatez en la defensa de algunos dere- 
chos fundamentales y en la duración media con que, en cambio, se resuelven los recursos.

El Tribunal ha tratado de establecer desde el principio los requisitos exigibles para la interposición y admisión del Recurso de Amparo sin gran éxito, habida cuenta del alto porcentaje de Autos de inadmisión que sigue habiendo y de la progresiva condena en costas e imposición de multas a que ha debido recurrir. Es él mismo quien resume la situación, en reciente sentencia (de 15 nov. 1990, f.j. 5), del siguiente modo:

"...cabe a este respecto señalar que la insuficiencia del desarrollo legislativo del art. 53.2 C.E. al no posibilitar mediante un recurso jurisdiccional previo y sumario ni mediante la adecuación a la C.E. de las normas procesales, la corrección de esas vulneraciones, convierte al amparo constitucional en un recurso subsidiario pero también común y general de última instancia respecto de todas las vulneraciones en procesos ordinarios que causen indefensión cuando haya sentencia firme. De este modo, la falta de un amparo que sea realmente previo y sumario ante los tribunales ordinarios, que hace revertir a éste toda la masa de recursos fundados en aquellos motivos, puede, en definitiva, repercutir en perjuicio de los particulares afectados al introducir, en todo caso, una instancia jurisdiccional más para la satisfacción de sus demandas".

Sin perjuicio de la responsabilidad de los poderes públicos y, especialmente del legislador, tal vez convenga reparar en alguna otra razón que pudiera confluir en semejante uso inoportuno y desmesurado del amparo constitucional. $Y$ quizás no fuera baldio analizar qué factores concurren en la presión social ejercida sobre el Tribunal Constitucional para convertirlo en Tribunal de apelación general, y ello, sin perjuicio de los efectos que la redacción del art. 50 LOTC operada por la L.O. 6/1988 pudiera comportar en la detención de la avalancha de amparos a que se ve expuesto el T.C. Pues lo que pudiera ser grave es la eventual imprudencia de los representantes legales del ciudadano $y$, peor aún, la falta de sensibilidad de éste ante la concepción y protección real de los derechos constitucionales en general y de cada grupo en particular.

En cualquier caso, es evidente que a esa hipotética irresponsabilidad ciudadana $y$, por supuesto, a la situación de deterioro a que se puede llegar en la actual confusión, contribuye decididamente la inactividad parlamentaria en punto al desarrollo del art. 53.2. La ley $62 / 78$ ha cumplido, lógicamente, la función que con carácter provisional asumió pero, a juzgar por la expresión de su propia Disposición final ( «... y entretanto se regula definitivamente el procedimiento jurisdiccional de amparo o tutela de los derechos reconocidos en la misma...") no nació con estructura y entidad 
suficiente para una larga interinidad. Prueba de ello es la progresiva ampliación de su ámbito (a través del R.D. 342/1979, de la Disposición Transitoria 2. ${ }^{a}$ LOTC y, recientemente, de la LPA de 1990) y las disfunciones observadas en su aplicación, principalmente en la especialidad procedimental de lo contencioso administrativo, como los administrativistas han puesto de relieve, amén de las lagunas que aún existen en punto a su ámbito de aplicación.

Pero, dejando por ahora las particularidades del art. 53.2, hemos de seguir con el cambio de enfoque más arriba enunciado a modo de hipótesis de trabajo $y$, en este sentido, lo que sugerimos ahora es la conveniencia de profundizar algo más en el ámbito de aplicación de los párrafos 1 y 3 del art. 53 con ese carácter integrador a que nos acabamos de referir.

El planteamiento, creo, es respetuoso con el esquema constitucional (piénsese en los artículos 1.1, 9.2, 10.1, etc... y en la propia expresión "informarán la práctica judicial» del art. 53.3) y su efectividad sólo requiere que el operador jurídico tenga presente la "filosofía de la libertad". Respecto de este último aserto, Francia o Italia nos ofrecen interesantes ejemplos, pues tratándose de sistema de reconocimiento de derechos no especialmente protegidos a nivel constitucional como lo están nuestros derechos fundamentales y libertades públicas han sabido, sin embargo, ir ampliando su protección tanto por la acción del legislador como, fundamentalmente, por la de la interpretación jurisdiccional.

Quiere decirse con ello que, si bien la literalidad de nuestro texto constitucional ofrece tres niveles de derechos, la existencia de un núcleo de ellos que, llamamos fundamentales, gozan junto a las libertades públicas de una especialísima protección, ello no puede suponer la minusvaloración de los restantes. Por eso, se intenta ahora un enfoque, que en parte ya hemos defendido en otras ocasiones, en el que ese núcleo de derechos con superprotección constitucional no sea la regla sino la excepción porque, si suponen un "plus" de protección respecto de los restantes derechos constitucionales, ello no significa que la base más amplia de los mismos quede insuficientemente protegida.

En primer lugar, porque estamos ante derechos constitucionales por su naturaleza y por su expresa y particularizada mención en el texto constitucional. En segundo lugar, porque no otro sentido puede tener el art. 53.1 que no en vano se refiere inicialmente a todos los derechos y libertades para, después, referirse en el párrafo siguiente a sólo una parte de ellos, la superprotegida. En tercer lugar, porque sólo un especial propósito garantista explica el contenido de dicho párrafo primero de alguna de cuyas proposiciones se ha afirmado que está vacía de contenido o que es innecesaria. 


\section{El artículo 53.1}

Ciertamente, puede parecer que todo el párrafo primero del art. 53 es redundante y por ello, tal vez los términos de la discusión doctrinal habrían de situarse más en torno a su oportunidad que a su necesidad.

Mientras permanezcamos en el ámbito del estricto análisis jurídico, si puede resultar innecesario afirmar la vinculatoriedad de todos los poderes públicos a los derechos y libertades, como también lo es, en puridad, el propio art. 9.1. $\mathrm{Y}$ nadie, sin embargo, ha discutido la oportunidad de este último del que se han extraído consecuencias de gran calado, como el principio de constitucionalidad o la normatividad constitucional cuyos efectos trascienden a todo el ordenamiento jurídico y hasta la propia concepción del Derecho y del Estado.

En el mismo sentido, creo que pueden extraerse profundas consecuencias de la primera de las afirmaciones del art. 53.1: De innegable oportunidad, es también necesaria como símbolo de ruptura con la tradicional concepción de una parte dogmática de las Constituciones en la que la normatividad se elevaba hasta el Derecho natural, pasando por alto a los operadores jurídicos; éstos no han estado ausentes en la conflictividad inherente a la defensa de los derechos e intereses del Derecho Privado. Tampoco habrán de estarlo, ha debido disponer el constituyente, a partir de 1978, en la tutela de cuantos derechos sean inherentes a la dignidad de la persona.

Pero, además, hay en este precepto peculiaridades semánticas que conviene precisar por cuanto abogan en favor de su oportunidad: si en el art. 9.1 se afirma que los ciudadanos y los poderes públicos están sujetos a la Constitución y al resto del ordenamiento jurídico, en el 53.1 se dice que los derechos y libertades "vinculan" a todos los poderes públicos. Basta consultar el Diccionario de la Real Academia Española para constatar la dimensión de permanencia o, mejor, perpetuidad que es inherente a este último vocablo.

Alguna reflexión también queremos hacer sobre la interpretación llevada a cabo hasta ahora, en torno a los elementos introducidos por la Constitución como garantías normativas, porque no sé si ha sido la más apropiada. De una parte, porque sus aspectos principales pueden haberse interpretado restrictivamente: es el caso del contenido esencial de los derechos cuya consideración de "mínimo" intangible parece haberse convertido en lugar común como, en aguda crítica a su introducción en el texto constitucional y sobre todo a su interpretación restrictiva, han puesto de 
relieve PRIETO SANCHÍS, así como CRUZ VILLALÓN siguiendo a DE OTTO.

De otra parte, la reserva de ley no debe suponer sino exclusión del ejecutivo a la hora de regular el ejercicio de los derechos y, por tanto, no es sino reserva de competencia en favor del Parlamento o, lo que es lo mismo, sólo a éste incumbe la regulación del ejercicio de los derechos y libertades. Ahora bien, no sé si, en un exceso de celo, se está interpretando esta reserva de ley como un deber de regulación. Ésta es sin duda necesaria para actualizar los medios de defensa, de conformidad con la Constitución y tal vez, como dice el propio precepto (art. 53.1) para regular el «ejercicio de los derechos y libertades" pero, a mi juicio, ésta es una facultad de la que habría que usar cautelosamente por cuanto la regulación, de no ser estrictamente necesaria, no lleva sino a introducir nuevos elementos que se interponen en la labor de interpretación constitucional, que en última instancia ha de llevar a cabo el Tribunal Constitucional: los derechos y libertades, quiérase o no, lejos de desconstitucionalizarse por la labor del legislador como en otros tiempos ocurriera, no abandonan el ámbito constitucional que les es propio por lo que el desarrollo legislativo no reduce, antes bien, puede aumentar la labor del Tribunal Constitucional, tanto en el volumen de los asuntos como en la complejidad de los mismos.

Creo, por lo demás, que este enfoque "restringido" es coherente con las expresiones del texto constitucional: "sólo por ley... podrá regularse el ejercicio...". No es que la ley tendrá que regular con carácter imperativo sino que lo que se quiere decir es que cuando proceda la regulación del "ejercicio", necesariamente tendrá que ser el legislador quien la lleve a cabo. Ni que decir tiene que esta interpretación se mantiene igualmente para la reserva de ley orgánica operada en el art. 81 que, a su vez y respecto de la reserva de ley, general u ordinaria, ha interpretado también restrictivamente el Tribunal Constitucional, consciente del riesgo de urigidificación» que sobre el ordenamiento jurídico puede operar. Más aún, esta consideración "restringida" o cautelosa de la reserva de ley habría de tener una mayor incidencia en la reserva de L.O. puesto que ésta afecta a sólo los Derechos Fundamentales y Libertades Públicas (comprendidos como bien se sabe en la Sec. $1{ }^{a}$ del Cap. II del Tít. I) y éstos como también PRIETO SANCHIS observa, son los menos necesitados de regulación porque no son (como sí, en cambio, son los principios rectores) normas fragmentarias sino que aparecen prácticamente acabadas en la propia Constitución. 


\section{El artículo $\mathbf{5 3 . 3}$}

Bien distinta es, ciertamente, la posición constitucional del capítulo III. Sus dictados, sin perjuicio de que estén comprendidos en la general protección que el constituyente establece en algunos preceptos para todo el Título (ejemplo, el art. 54) requieren un enfoque diverso al del capítulo II; así lo exige una interpretación global de los distintos párrafos del art. 53. No porque dicho capítulo carezca de valor jurídico, sino porque su formulación no se lleva a cabo desde la perspectiva de la defensa jurídica o exigencia inmediata por el ciudadano de sus derechos ante las instancias pertinentes sino desde la perspectiva de la conminación a los poderes públicos para que, en línea con lo establecido en el art. 9.2 inicien una política social y económica sin la cual los propios derechos fundamentales peligran o se empobrecen.

No hay, desde luego, en nuestra Constitución a diferencia de la portuguesa, una obligada revisión periódica, pero si hay un sentido del tiempo o de la progresión que tal vez ha sido descuidado por la reflexión académica. La idea del tiempo está presente en la construcción del Estado social y democrático de Derecho. No porque se programen las dilaciones, pues los mandatos que con carácter imperativo contiene el capítulo III para los poderes públicos, tienen la inmediatez de la propia vigencia constitucional, sino porque el constituyente parece ser consciente de que la realización del Estado como social y democrático de derecho no se lleva a cabo con la sola promulgación constitucional, sino con la adopción de medidas económicas y fiscales y con la consolidación de políticas estatales como las que se contienen en los principios rectores de este capítulo III y, es evidente, ello exige una actividad de "progresión" en la que el tiempo no puede ser un factor ausente.

Todo lo cual no empece para que desde el primer momento, los principios rectores configuren "mínimos" garantizados que, en espera de su desarrollo (aquí sí es importante y urgente la labor del legislador), imponen el deber de respeto por parte de todos los poderes públicos como el Tribunal Constitucional ha puesto de relieve. Asi, por ejemplo, la consideración del artículo 41 C.E. le llevó a calificar de caduco un sistema de seguridad social basado en el principio contributivo y de compensación frente al daño cuando el criterio que ha de prevalecer es el de protección frente a la necesidad o la pobreza (sent. $103 / 83$ y 65/87).

En este sentido, creo que es hora ya de reivindicar el papel del capítulo III (como recientemente lo han hecho entre nosotros CASCAJO o PRIETO SANCHís) cuya lectura, a la luz del art. 53.3, nos sugiere las siguientes consideraciones: 
En primer lugar, el constituyente utiliza con acierto la expresión "principios rectores", pues de principios o directrices a desarrollar se trata. Directrices o principios que los poderes públicos no pueden ignorar, antes bien, han de desarrollar en todo lo posible pues no en vano la mayoría de los preceptos comienzan con la mención de los poderes públicos por ser los destinatarios, y por tanto, los obligados, del mandato de hacer que cada uno de tales preceptos contiene. Todo el capítulo III constituye, en rigor, un desarrollo coherente del precepto contenido en el art. 9.2.

En segundo lugar, tal vez se ha rehuido la formulación de derechos en el mismo por la carga de exigibilidad que éstos comportan y las consecuencias que podrían suponer en un sistema que sólo puede garantizarlos previas las políticas oportunas y la previsión de los medios necesarios. En los pocos casos en que se mencionan (el derecho a la salud, al disfrute del medio ambiente, al acceso a la cultura o a una vivienda digna) no parece sino que se está justificando la necesidad de las medidas sociales y políticas cuyo fundamento lo constituyen tales derecho formulados aquí no con carácter individual, sino en su dimensión más social y general que entronca con el art. 10.1 de la propia Constitución.

En tercer lugar, la extraordinaria debilidad que en el capítulo III se ha querido ver a partir de lo dispuesto en el art. 53.3, tal vez pudiera hoy revisarse tanto desde un punto de vista jurídico como desde el sociopolítico. Aparte la normatividad del mismo que, como parte de la Constitución es indiscutible ex art. 9.1 el desarrollo jurídico de alguno de tales principios, (por lo demás ya existente en algunos aspectos aun antes de la Constitución), creo que es relevante. Baste citar como ejemplo la introducción en la legislación penal del delito ecológico o las disposiciones en torno al uso del tabaco en lugares públicos. La defensa, así, de los intereses constitucionalmente protegidos se lleva a cabo en las diferentes ramas jurídicas en que aquéllos van introduciéndose, sin olvidar, además, la protección que puede derivarse de su vinculación o implicación en cada caso concreto con un derecho fundamental o una libertad pública. $Y$ en punto al desarrollo normativo no podemos dejar de mencionar la incidencia que la integración de España en la Comunidad Europea tiene pues, más allá del valor interpretativo de los Textos Internacionales impuesto por el art. 10.2 C.E., nos referimos ahora a la aplicación interna del Derecho Comunitario, prolijo, por cierto en el desarrollo de algunos principios rectores. Se diría así, que la hipotética negligencia del legislador español quedaría paliada por efecto de tal integración europea. En cualquier caso y por lo que después diremos sobre la enseñanza y la sensibilización ciudadana en esta materia, vale, tal vez, la pena observar que entre los objetivos que la LOGSE (octubre de 1990) establece como mínimos para la enseñanza secunda- 
ria se lee en el art. 19, lo siguiente: "Valorar críticamente los hábitos sociales, relacionados con la salud, el consumo y el medio ambiente».

En cuarto lugar, tal vez el aspecto menos relevante de este capítulo sean los derechos en su tradicional versión individualista y frente al Estado (derechos públicos subjetivos) que la sola mención del vocablo representa. Pues los beneficios e intereses anejos a la realización de los principios rectores son colectivos, difusos si se quiere, y afectan a todos como acreedores (lo que explica que en algunos casos se reconozca, bien que con cautelas, la acción popular: así, en la Ley del Patrimonio Histórico de 1985 $y$ en la Ley de Costas de 1988) pero también a todos convierten en obligados o en su realización. En algunos casos se dice con claridad (al deber de conservar el medio ambiente se refiere el art. 45); en otros, es una realidad o presupuesto sobreentendido (la referencia a la redistribución de renta del art. 40 o los deberes de "todos" para con la salud pública a que se refiere al art. 43). Es ésta una perspectiva que aparentemente choca con la construcción dogmática de los derechos tradicionales $y$, a lo sumo, sería aplicable al Cap. III de la C.E. Sin embargo, podría también ofrecernos una "zona de luz" (como BOBBIO denomina los avances de los derechos) en la medida en que contribuyera a crear una mentalidad de respeto, también de los Derechos Fundamentales y Libertades Públicas, una "militancia» ciudadana por la protección de la dignidad humana, respecto de la cual las garantías personales no serían sino remedios excepcionales actitudes también excepcionales.

En quinto lugar, y por lo hasta aquí expuesto, el Cap. III no es tal vez un capítulo de derechos tradicionalmente entendidos pero sí lo es de solidaridad y, por ende, de respeto a los derechos ajenos y a los de la colectividad. Es por ello por lo que el capítulo III del Título I, si se presenta como el menos protegido, ofrece peculiaridades que permiten afirmar, de una parte, su importancia e incidencia en la realización de las propias Libertades Públicas y Derechos Fundamentales del Cap. III (de su "carácter instrumental" se habla a menudo citando la interpretación de CALAMANDREI sobre la Constitución italiana) y, de otra, su interés y funcionalidad como parámetro de la actuación de los poderes públicos y de la sensibilidad social en materia de derechos. Procede aquí, de nuevo, concordar este enfoque con el que el propio texto constitucional mantiene en el art. 10.1. 


\section{LA CULTURA DE LOS DERECHOS Y LAS LIBERTADES COMO TAREA ESENCIAL DEL ESTADO CONSTITUCIONAL}

Con insistencia se refiere HÄBERLE a la imbricación cada vez mayor entre los derechos fundamentales y las tareas del Estado. Desde esta perspectiva, toda la configuración del Estado social y democrático de Derecho parece ofrecer nuevos perfiles y trasciende las principales instituciones del Estado lo que lleva al autor citado a afirmaciones del siguiente tenor: «El diputado se convierte en agente fiduciario de los derechos fundamentales de los ciudadanos ... El Parlamento es responsable de la política de los derechos fundamentales...". En definitiva, "la cultura de los derechos fundamentales deviene, así, el mensaje cifrado de una evolución de los derechos fundamentales en la que todos participan".

Pues bien, todo ello no tiene ningún sentido si tal "cultura" de los derechos fundamentales no se entiende en su acepción más amplia, si la sensibilidad por los derechos a que más arriba hacíamos referencia no alcanza también al ciudadano. «El actual planteamiento constitucional de la democracia participativa y pluralista, dice MARTíN RETORTILLO, arranca, por definición, de un abierto protagonismo de los ciudadanos". Pero, como el mismo autor advierte, la introducción de los hábitos participativos es una operación compleja que no se puede improvisar.

La referencia a la participación ha de entenderse, en mi opinión, en el sentido más amplio o, si se quiere, ha de pensarse en la participación en la "cultura de los derechos", en el fomento de su realización y respeto por todos. En cualquier caso, la consecuencia es obvia y la expone el mismo autor apenas citado: "Surge así la indeclinable necesidad de educar para las libertades, siempre necesaria, si se tiene en cuenta el relevo de las generaciones, pero especialmente menesterosa en sociedades como la española, tantos años orientada por criterios contrarios. Es como si la educación resultara connatural a la propia proclamación de las libertades". Tal vez, habríamos de rectificar en el sentido de que educación resulta connatural, no tanto con la proclamación, cuanto con la "vinculatoriedad" de los derechos.

\section{Operatividad del enfoque}

Ya en otras ocasiones me he ocupado de la importancia del estudio de los derechos y libertades asi como de la precariedad del mismo en los distintos niveles de nuestro sistema educativo. En ésta, he querido 
plantear mi reflexión en torno a los dos autores citados en este epígrafe porque creo que aportan manifestaciones novedosas, al menos para quien ahora escribe. Ciertamente, llama la atención la generalización que del problema hace MARTíN RETORTILLO cuando, más allá del estricto ámbito docente hace un llamamiento, para "desempeñar una importante labor tuitiva, de vigilancia $y$ de incitación» a todos los que "de cualquier manera contribuyen a formar opinión pública: maestros, y enseñantes, escritores y artistas, líderes sociales, periodistas...".

En cuanto a HÄBERLE, la «interpretación abierta de los derechos fundamentales" le lleva a que en la misma se atienda al propio sentir, o a la concepción que de cada uno de ellos tienen sus titulares y hasta a concluir con un cierto reproche a la doctrina alemana por la pérdida de aliento e imaginación que su apego a la jurisprudencia del Tribunal Constitucional viene comportando. Pero el autor no olvida tampoco la importancia de la enseñanza y, convencido del papel que en la eficacia de los derechos juega su protección por el Estado "en cuando fines educativos", enumera las Constituciones que han previsto esta dimensión de los derechos: desde las Constituciones de los Länders alemanes a recientes Constituciones iberoamericanas, sin olvidar, lógicamente, el art. 26.2 de la Declaración Universal de 1948.

Llegados a la universalidad, omnipresencia e internacionalismo de los derechos fundamentales poco más se puede hacer, viene a decir, desde las categorías y enfoque tradicionales: «En el Estado constitucional los derechos fundamentales no pueden ser abarcados suficientemente por un tiempo con el convencional concepto de eficacia concebido, sea jurídica, sea sociológicamente. De lo que andamos solícitos es de la categoría de "cultura de los derechos fundamentales".

Con el bien entendido de la amplitud y tal vez, por ello, imprecisión científica con que se ha venido usando el término cultura, sea sobre este enfoque comprensivo, sea desde el más limitado de la enseñanza, es fácil encontrar elementos en nuestra Constitución que dan soporte jurídico a este planteamiento que, si puede parecer simplista o poco dogmático, es sin duda el más efectivo y duradero (bien que de lenta implantación) de los que persiguen que los derechos y las libertades del individuo y los grupos (tal como reza el artículo 9.2) sean reales y efectivos. Por no ir mucho más allá del Título Preliminar, creo que el planteamiento halla un firme soporte en los valores superiores del ordenamiento jurídico, en el artículo 9.2 que acabamos de mencionar y muy especialmente en el artículo $10.2 \mathrm{cu}$ yos asertos, cada uno en particular y todo el precepto en general, son una invitación a no quedar anclados en lo jurídico, en las técnicas, categorías y procedimientos para llegar al "sentimiento" y al compromiso con cuanto constituye el fundamento del orden político y de la paz social. 
Tal vez con este enfoque, aceptando que el fomento de la cultura de los derechos fundamentales es tarea inexcusable del Estado constitucional (por seguir con la terminología de HÄBERLE) cobra todo su sentido el Preámbulo de la Constitución española, del que bien poco solemos decir y que, en cambio, cobra virtualidad en el intento de extraer todas las consecuencias de los mandatos constitucionales en materia de derechos ino sólo los fundamentales sino de todos los derechos constitucionales) porque así viene a representar la meta o la imagen de la sociedad española como resultado de esa efectividad que sólo se alcanza con la concurrencia de todos, poderes públicos y también ciudadanos.

\section{La enseñanza de los derechos en España}

Pues bien, en esa magna tarea estatal y social, la enseñanza ocupa un papel insustituible que tampoco es ajeno al constituyente cuando, en el artículo 27 (que en principio no tiene por qué referirse sino a la educación abstractamente considerada) vincula ésta a los derechos y libertades fundamentales volviendo de nuevo (aún sin mención expresa) a los contenidos del artículo 10.1. El texto, creo, es todo un símbolo y merece ser reproducido:

"La educación tendrá por objeto el pleno desarrollo de la personalidad humana en el respeto a los principios democráticos de convivencia que a los derechos y libertades fundamentales».

Al reflexionar sobre el precepto, dirá CÁMARA que, aunque la Constitución no tipifique un modelo de enseñanza (como si tipificaba la II República española), ello no quiere decir que sea neutral pues "contiene, por el contrario, su propio ideario que no es otro sino el de la educación democrática sin otras determinaciones». Desde diversos ámbitos cientificos se ha demostrado ya la interrelación entre educación y democracia $y$, por lo demás, se trasluce en la redacción de los documentos internacionales que constituyen parámetros de interpretación de nuestro sistema de derechos de conformidad con lo que el artículo 10.1 establece. Pero tal vez la más aguda de las consideraciones en este punto la debemos a DE OTTO como el propio CÁMARA recuerda. Al argumentar sobre la ausencia entre nosotros de una concepción beligerante de la democracia que sí existe, en cambio, en Alemania, observa DE OTTO que la única mención que se hace en la Constitución española al orden liberaldemocrático como un todo, prohibiendo el abuso de derechos contra él, es precisamente la expresada en el artículo 27.2. 
La idea, por lo demás, se repite en la normativa de desarrollo. Así, entre los fines que la LODE, de 1985, señala a la actividad educativa su artículo 2.b) comprende el de "la formación en el respeto de los derechos y libertades fundamentales". Y en el preámbulo de la LOGSE, de 1990, tras señalar que el objetivo primero y fundamental de la educación es el de la plena formación de la juventud, añade: «tal formación plena, ha de ir dirigida al desarrollo de su capacidad para ejercer de manera crítica y en una sociedad axiológicamente plural la libertad, la tolerancia y la solidaridad. En la educación se transmiten y ejercitan los valores que hacen posible la vida en sociedad, singularmente el respeto a todos los derechos y libertades fundamentales, se adquieren los hábitos de convivencia democrática y de respeto mutuo, se prepara para la participación responsable en las distintas actividades e instancia sociales...".

Más aún, apenas publicada la Constitución, el legislador se ocupó del tema con la Ley 19/1979 de 3 de octubre por la que se reguló uel conocimiento del ordenamiento constitucional" que habría de impartirse a los alumnos de BUP y de FP de $1 .^{\circ}$ Grado. Del breve contenido de dicha ley, así como de las disposiciones de desarrollo conviene subrayar al menos dos ideas: 1. Su objetivo, que es el de llevar hasta los jóvenes el conocimiento del texto fundamental como instrumento decisivo para la consolidación de la democracia. 2. Los criterios o método a seguir en el cumplimiento de la obligación legal: no se trata de imponer la adquisición de unos datos o conocimientos mínimos del texto fundamental (por lo que esta materia no está sujeta a evaluación) sino de fomentar la motivación del alumnado hacia estas cuestiones.

La ley sigue vigente, a juzgar por la mención que de la misma se hace en la disposición final 4.4 de la LOGSE de 1990 y sin embargo, hasta donde yo sé, bien escaso es su cumplimiento por no decir que nulo en el ámbito geográfico valenciano, y no parecen más alentadores los resultados en otros ámbitos a juzgar por las noticias de prensa (en concreto, la más reciente, sobre la Comunidad de Madrid, según $A B C$ de 18.4.92).

He aquí por qué, decíamos al principio, no bastan los cauces jurídicos, urge el compromiso de los poderes públicos y el interés colectivo por hacer realidad esa cultura de los derechos. 


\section{REFLEXIÓN SOBRE EL CAPÍTULO V O LA SUSPENSIÓN DE GARANTIÁAS}

Mi intervención ha de referirse, también, a la suspensión y lo haré con mayor brevedad aún que lo he hecho sobre el artículo 53. Tampoco sobre el artículo $\mathbf{5 5}$ he de proponer reformas ni justificar la conveniencia o no de las mismas. El problema de este artículo 55, creo, es el mismo del 53, el de su aplicación y respeto hasta las últimas consecuencias. Puede discutirse si realmente era necesaria la suspensión individual del párrafo $2 .^{\circ}$ pero, en cualquier caso, lo que es evidente es que uno y otro párrafo del artículo 55 no hacen sino constitucionalizar el derecho excepcional y, en tal medida, limitar el margen de interpretación con que el legislador, los jueces y la propia doctrina en el Derecho comparado ha tenido que salir al paso de problemas semejantes a los que el constituyente español previó en este artículo.

Podría discutirse, de otro lado, la oportunidad de que el propio Estado de Derecho reconozca al máximo nivel (constitucional) su incapacidad para aplicar el Derecho y tal vez con la perspectiva que estos años de experiencia constitucional nos ofrecen podría resultar más preocupante aún tal reflexión si ni siquiera la previsión constitucional, ni el subsiguiente desarrollo normativo, hubiera surtido el efecto deseado. Pero no es éste el objeto de esta aproximación brevísima, y existen, por lo demás, estudios especializados sobre el tema que obvian la pertinencia de pensamientos sintéticos sobre lo que no ha sido objeto de detenido estudio por mi parte.

\section{Respeto de los derechos es, también, respeto a su ususpensión»}

Pretendo ahora, tan sólo, sugerir un enfoque para un posterior análisis y expresar la preocupación que la realidad normativa más reciente pudiera plantear. $Y$ todo ello, insisto, a modo de hipótesis de trabajo. La razón última de tal ensayo a realizar no es otra que el respeto máximo, ya se ha dicho, a los derechos y libertades y más consecuentemente a la mente del constituyente en la medida en que el nivel de aquéllos en ella es aceptable.

En efecto, conocidos ya los contenidos jurídicos del artículo 55 (rigurosamente estudiados, principalmente por CRUZ VILLALÓN y FERNÁNDEZ SEGADO) y su concordante 116 (tempranamente desarrollado por el legislador) basta recordar la filosofía de los mismos, la excepcionalidad de 
los supuestos que tratan de prever y mantener dentro del orden constitucional, para percatarse que el problema no se plantea, o no necesariamente, con la aplicación de tales supuestos, pues la excepcionalidad de su regulación trata de ser compensada con las previsiones y garantías del artículo 116 e incluso, las del artículo 55.2, aunque, ciertamente, son mucho más vagas.

El problema pudiera presentarse si se tratara de aplicar la filosofía del artículo 55 sin la excepcionalidad (de situaciones, personas y hasta tiempo pues no se concibe una excepcionalidad permanente) que le es inherente $y$ además sin los controles a que la Constitución somete tales medidas excepcionales.

\section{El riesgo a «normalizar» el Derecho excepcional}

El peligro quedó lúcidamente expuesto por CRUZ VILLALÓN al admitir que no existiendo límites temporales en el artículo 55.2 por no quedar señalado plazo alguno, en alguna medida cabría la fabricación de un estado excepcional "a medida" superpuesto a la situación de normalidad y que produce el desplazamiento del propio estado de excepción. Evidentemente, las garantías del artículo 53 resultarian vanas si, alegando la necesidad que está en la base del derecho excepcional, no se respetasen, sin embargo, las reglas de éste.

Tal es, sin duda, la razón por la que las LL.OO. "antiterroristas" de 1988 (o de reforma del C.P. y de la L.E. Crim.) han sido criticadas al introducir preceptos de carácter excepcional en el Derecho de la normalidad constitucional.

No es éste el lugar para emprender una reflexión sobre los elementos de excepcionalidad que en punto a derechos y libertades pueda contener la reciente y polémica Ley de Seguridad Ciudadana. Bastará ahora apuntar el interés de su análisis desde la perspectiva sugerida y, más aún, el interés de un estudio comparado entre esta Ley y la 4/81 (conocida como "ley de estados") tendente a poner de relieve las garantías de que en uno y otro caso se acompaña cada suspensión de garantías (valga la paradoja).

No pudiendo ahora detenernos en todo ello y habiendo excedido ya el límite dispuesto será oportuno recordar que estas cuestiones, como la concreta de fijación o no de plazos en los supuestos del art. 55.2 en que no la ha establecido el constituyente, quedan a expensas de lo que CRUZ VILLALÓN denomina "sensibilidad constitucional». 


\section{BIBLIOGRAFÍA}

Bоввіо, N.: El tiempo de los derechos. Madrid, Ed. Sistema, 1991.

Cascajo Castro, J.L.: "La Tutela Constitucional de los Derechos Sociales", en Cuadernos y Debates, n. ${ }^{\circ}$, Madrid, C.E.C., 1988.

Cruz VILlalón, P.: Estados excepcionales y suspensión de garantías. Madrid, Ed. Tecnos, 1984.

Fernández Segado, F.: "Comentarios al artículo 55», en Constitución Española de 1988, dir. por Ó. ALZAGA, Edersa, vol. IV, 1984.

López GuerRa, L. y otros: Derecho Constitucional. Valencia, Tirant lo Blanch, 1991.

López PinA, A.: La garantía constitucional de los Derechos Fundamentales. Alemania, España, Francia e ltalia. Madrid, Cívitas, 1991.

Martín Retortillo Baquer, M.: "Eficacia y garantia de los Derechos Fundamentales», en Estudios sobre la Constitución Española en Homenaje al Prof. García de Enterría. Madrid, Civitas, 1991.

OCCHIOCUPO, N.: Liberazione e promozione umana nella constituzione. Milano, Giuffré, 1988.

Prieto Sanchis, O.: "Comentario al capitulo IV del Título I romano», en Constitución..., dir. por Ó. Alzaga, cit.

-: Estudios sobre Derechos Fundamentales. Madrid, Debate, 1990.

SÁNCHEZ FERRIZ, R.: Estudio sobre las Libertades. Valencia, Tirant lo Blanch, 1989.

Torres del Moral A.: Principios de Derecho Constitucional Español. Madrid, Servicio de Publicaciones de la Facultad de Derecho de la Universidad Complutense, 1992.

VV.AA.: 3 vols, publicados por la Dir. Gral. del Servicio Juridico del Estado bajo el título: Introducción a los Derechos Fundamentales. Madrid, 1988. 